\title{
Dental effects of fluoridation of water with particular reference to a study in the United Kingdom
}

By E. R. Bransby and J. R. Forrest, Ministry of Health, Alexander Fleming House, Elephant and Castle, London, S.E.I, and J. N. Mansbridge, Department of Public Health and Social Medicine, Usher Institute, Warrender Park Road, Edinburgh, 9

\section{Plan of the study}

Fluoride is present, naturally, in almost all water supplies, usually in trace amounts, but in many parts of the United States it occurs in concentrations of between $\mathbf{I} \cdot 0$ and $8 \cdot 0$ p.p.m. It was in that country that most of the earlier research into its effect on dental conditions was done and that the beneficial effect of relatively low levels of fluoride in the drinking water was first demonstrated. As a logical extension of that research the idea was conceived of adding fluoride to some water supplies to see if the same beneficial effect could be obtained; accordingly in 1945 controlled fluoridation studies were set up in two areas in the United States and in one in Canada.

Fluoride was added to the water supplies in these areas to give a concentration of from $\mathrm{I} \cdot \mathrm{O}$ to $\mathrm{I} \cdot 2$ p.p.m., the level which epidemiological studies had shown to give maximum protection to the teeth without causing enamel mottling. The studies were planned to last for at least ro years so that the effect of fluoridation during the whole period of development and calcification could be assessed on both the deciduous and permanent dentitions. Interest in fluoridation was aroused in this country by the results achieved in these studies after even 5 years. A mission was sent by the British Government to study fluoridation in operation and to assess its effectiveness, safety and practicability. The mission reported favourably (Ministry of Health, Department of Health for Scotland, Ministry of Housing and Local Government, I953) but recommended that, before the general adoption of fluoridation, its effect should be demonstrated in a few selected areas in the United Kingdom. Accordingly studies were begun in $1955^{-6}$ in three areas in the United Kingdom.

\section{Selection of areas}

The areas selected were: Watford in England, Kilmarnock in Scotland, and part of the county of Anglesey in North Wales. Three comparable areas were selected also, to serve as controls: Sutton, the town of Ayr and the remainder of the county of Anglesey respectively.

The main criteria for the selection of areas were that (I) the population should be large enough to provide adequate samples of children; (2) the study area and its associated control area should be situated near to each other and be of the same character; (3) the pairs of study and control areas should be in different parts of the country so that the effect of fluoridation could be assessed in different environmental and dietary conditions; (4) the water supplies of each study area and of its control area should if possible be from the same geological sources and undergo the same 
kind of chemical treatment before entering the domestic supply; (5) the water supplies of the study and control areas should have a negligible fluoride content.

Particulars of the study and control areas were:

Anglesey, N. Wales:

Bodafon zone, control

Gwalchmai zone, study

Holyhead, study

England:

Sutton, control

Watford, study

Scotland:

Ayr, control

Kilmarnock, study

\begin{tabular}{|c|c|c|c|}
\hline $\begin{array}{l}\text { Approximate } \\
\text { population }\end{array}$ & $\begin{array}{l}\text { Distance } \\
\text { apart } \\
\text { (miles) }\end{array}$ & $\begin{array}{l}\text { Nature of } \\
\text { locality }\end{array}$ & Water supply \\
\hline $\begin{array}{l}20000 \\
20000 \\
10000\end{array}$ & Adjacent & $\begin{array}{l}\text { Agricultural } \\
\text { Agricultural } \\
\text { Market and dock } \\
\text { town }\end{array}$ & \}$_{\text {Soft }}^{\text {Soft; from the same }}$ source \\
\hline $\left.\begin{array}{l}70-80000 \\
70-80000\end{array}\right\}$ & 30 & Mainly residential & $\begin{array}{l}\text { Hard, softened before } \\
\text { distribution }\end{array}$ \\
\hline $\left.\begin{array}{l}43000 \\
43000\end{array}\right\}$ & 12 & Mainly industrial & Soft \\
\hline
\end{tabular}

\section{Selection of children}

The aim, which was largely achieved, was to examine 100 children of each of the ages 3 and 4 years and 100-150 schoolchildren of each age in each area. Only those children were included who had lived in the area since birth, other than for short breaks such as annual holidays.

For the selection of preschool children, a list was compiled from available local sources. Children ineligible on the grounds of non-continuous residence were excluded; a representative sample of the remainder was then drawn. Mothers of the selected children were invited to bring the children to the clinic for examination; if such a procedure did not yield sufficient children, others attending infant welfare centres, day nurseries and nursery schools were included.

In the Gwalchmai and Bodafon zones of Anglesey, all the preschool children examined were selected from a list compiled as described above and were a reasonably good cross-section of Anglesey children of those ages. In Holyhead and in Watford and Sutton, children attending welfare centres, nurseries and nursery schools were included. Although the children in these areas might not be representative of all the children of these ages in the areas, they were derived from much the same groups of children each year. In Kilmarnock and Ayr a cross-section of children was examined each year together with the children in nurseries and nursery schools, but only the findings for the cross-section of children have been used.

The selection of schoolchildren presented no such difficulties. In the Gwalchmai and Bodafon zones of Anglesey all eligible schoolchildren up to 15 years of age were examined. In Holyhead only those up to the age of I I years attending primary and junior schools were included, as the senior schools have a mixed population, many of the children coming from outlying areas. In Watford and Sutton, Kilmarnock and Ayr, representative samples of children were drawn from the school registers.

\section{Dental examinations}

Several methods of dental examination have been used in fluoridation studies in America and elsewhere. In the majority, clinical methods are employed, that is, with 


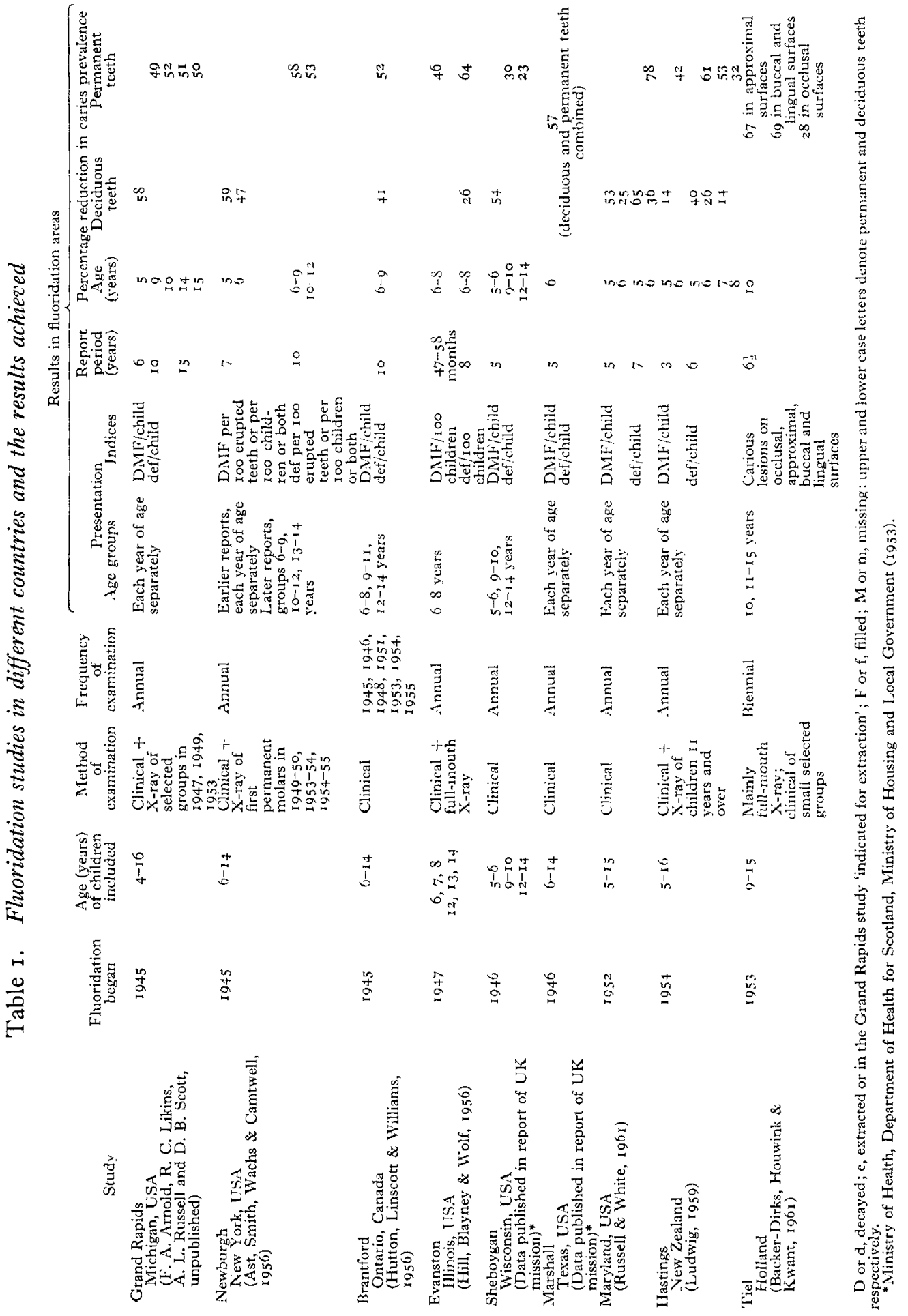


mouth mirror and probe. In some studies however, radiological examination is also included, either throughout the study or periodically. Table $\mathrm{x}$ shows for various studies in different parts of the world the type of dental examination, the groups studied, the indices used and the results obtained.

In the studies now described, clinical examination was preferred. The dental examinations were made by a number of dental officers, who both before and during the period of study were given a special course of training in the method of examination and recording. On two occasions during the study period, the assessments of caries made by the individual dental officers were compared; they, as one would expect, showed some variation. Diagnosis of early enamel lesions is often difficult, which usually explains the variations between assessments by dentists taking part in a survey.

The steps taken to improve the reliability of the dental examinations were: (I) the same dentists carried out the dental examinations in each pair of study and control areas, (2) each dentist examined children in the same schools on each occasion, and (3) each dentist examined during alternate weeks in the study and control areas.

This plan was, in the main, followed throughout the study period although for various personal reasons it could not be adhered to entirely. The dental findings presented in the official report of the studies (Ministry of Health, Scottish Office, Ministry of Housing and Local Government, I962) and in this paper were derived from those dental examinations that adhered strictly to this plan.

Only those lesions with definite breach of the enamel and palpable softening of the underlying dentine were counted as carious, that is cavities that should be filled and were thus of practical importance. The site and extent of each carious lesion was noted, the surfaces involved and the depth of penetration of caries being shown.

Although this was a clinical study, radiological examinations were carried out in I $95^{8}$ on 12-year-old children in the study areas in England and Wales, mainly to determine whether or not the use of radiographs would add materially to the value of the clinical examinations. The findings showed that the use of radiographs made little difference to the caries count.

\section{Index for assessing the effects of fluoridation}

The index for assessing the dental affects of fluoridation was the average number of decayed, missing and filled teeth per child. This index (DMF for permanent teeth, $\mathrm{dmf}$ for deciduous teeth) in which the tooth is the unit, is simple and easily understood. An Expert Committee on Dental Health of the World Health Organization (World Health Organization, I962) recommends its use in dental surveys. It is a measure of the lifetime experience of caries. As the object of fluoridation studies is eventually to assess the effect of fluoridation on children who have had fluoridated water all their lives, the total caries experience of the deciduous teeth and of the permanent teeth is an appropriate criterion.

For children aged 3 and 4 years, the full deciduous dentition was assessed, any missing teeth being counted as carious, because natural shedding of such teeth is unusual at those ages. For children aged from 5 to 7 years, only the deciduous canines 


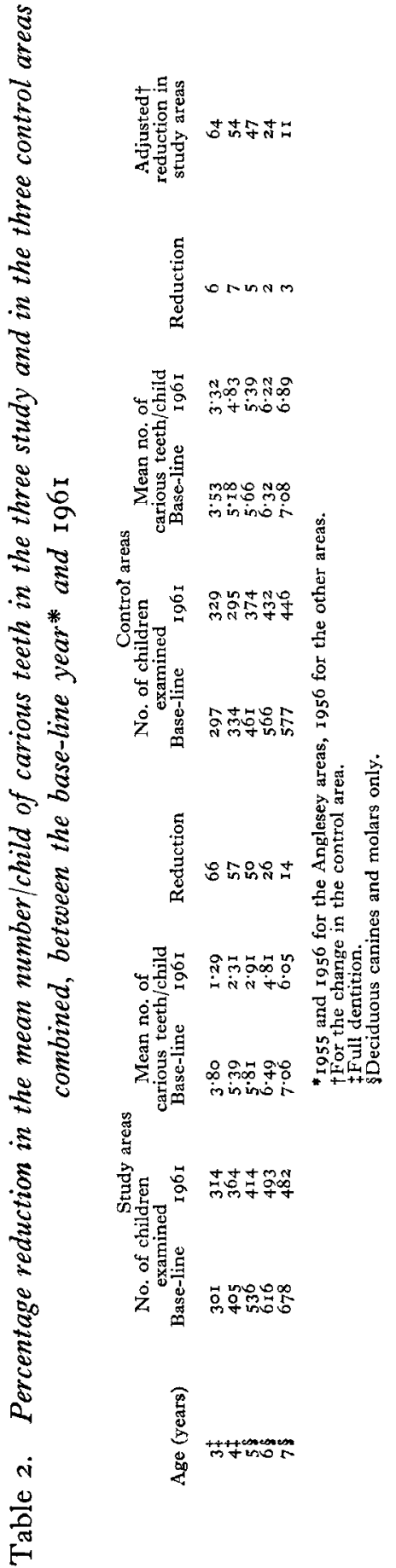


and molars were assessed (any of those missing, being counted as carious) to avoid complications arising from the shedding of the incisors, which is frequent at those ages.

\section{Results}

The effects of fluoridation were assessed from the trends over the study period, from the consistency of the results in the different study and control areas and from the findings for the study areas combined and for the control areas combined.

Table 2 shows the changes between the base-line years and $196 \mathrm{I}$ in the three study areas and the three control areas combined, together with the changes in the former after adjustment for the changes in the latter. The reduction was very substantial for the younger children; some reduction was apparent even for children aged 7 years. Table 3 shows the findings for the individual areas; the similarity between them is obvious.

Table 3. Percentage reduction* in the mean number/child of carious $\dagger$ teeth in the three study areas between the base-line year ${ }_{+}^{+}$and $\mathrm{I} 96 \mathrm{I}$

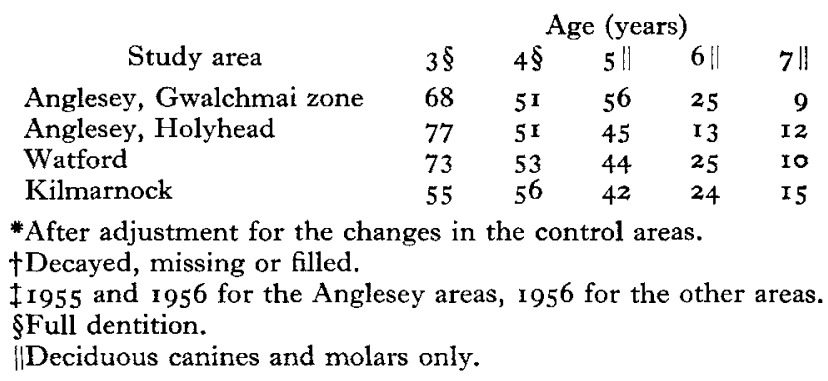

Table 4 shows, as an example, the changes in one fluoridation area, the Gwalchmai zone of Anglesey, for each year from 1957 to 196 I for children aged 3-7 years. Over the study period there was a reasonably consistent trend in the percentage reduction in the amount of caries and also from the younger to the older children. The results for the other study areas followed the same pattern.

Table 4. Mean number/child, in children aged $3^{-7}$ years in the Gwalchmai zone of Anglesey, of carious deciduous canines and molars in each of the years from 1957 to I $96 \mathrm{I}$, expressed as a percentage of the base-line number*

\begin{tabular}{|c|c|c|c|c|c|}
\hline $\begin{array}{c}\text { Age } \\
\text { (years) }\end{array}$ & 1957 & I958 & 1959 & I960 & I96I \\
\hline 3 & 98 & 87 & 24 & $5 I$ & 40 \\
\hline 4 & I 19 & $9 \mathbf{I}$ & $9 I$ & $3^{6}$ & 44 \\
\hline 5 & 99 & $9^{8}$ & 85 & 74 & 46 \\
\hline 6 & 102 & 90 & 9I & 79 & 73 \\
\hline 7 & IIO & 105 & 98 & 99 & 88 \\
\hline
\end{tabular}

The change over the study period in the mean number of carious teeth per child naturally affects the proportions of children with different numbers of carious teeth. Table 5 shows for the base-line years and $196 \mathrm{I}$ the proportions of children aged 3 
and 4 years with different numbers of carious teeth. For children aged 3 years the percentage free from caries rose from $32 \cdot 5$ to $60 \cdot 5$, while the percentage with ten or more carious teeth fell from $14^{\circ} 9$ to $1 \cdot 7$. The corresponding figures for children aged 4 years were from $22 \cdot 2$ to $42 \cdot 0$ and from $21 \cdot 6$ to $3 \cdot 6$.

Table 5. Percentage of children aged 3 and 4 years in the three study areas combined with different numbers of carious* teeth (deciduous teeth, full dentition)

\begin{tabular}{|c|c|c|c|c|}
\hline No. of & Children age & 3 years & Children age & 4 years \\
\hline carious teeth & Base-line $\uparrow$ & I $96 \mathrm{I}$ & Base-linct & I $96 \mathrm{I}$ \\
\hline$\circ$ & $32 \cdot 5$ & $60 \cdot 5$ & $22 \cdot 2$ & $42 \cdot 0$ \\
\hline 1 or 2 & $23 \cdot 2$ & 20.9 & 15.9 & $23 \cdot 4$ \\
\hline $3-5$ & $16 \cdot 5$ & $12 \cdot 2$ & 20.8 & $20 \cdot 7$ \\
\hline $6-9$ & 12.9 & $4 \cdot 7$ & 19.7 & $10 \cdot 3$ \\
\hline 10 or more & 14.9 & $I \cdot 7$ & $21 \cdot 4$ & $3 \cdot 6$ \\
\hline
\end{tabular}

* Decayed, missing or filled.

+r 955 and 1956 for the Anglesey areas, 1956 for the other areas.

The changes over the study periods in the three fluoridation areas in the individual deciduous teeth are shown in Table 6 and in the individual tooth surfaces in Table 7 . Both in the base-line period and in $196 \mathrm{I}$ caries experience was greatest in the molars and least in the canines and incisors. The results for the individual areas do not indicate any consistently different effect of fluoridation on the individual teeth. The surface most frequently affected was the occlusal, and least frequently the lingual. The results for the separate areas do not show a consistently different effect of fluoridation on the individual surfaces, although there is some suggestion of a lessthan-average reduction on the occlusal surfaces of the molars.

Table 6. Percentage reduction in the mean number of carious teeth $(a, b, c, d$, $e$, separately) (deciduous teeth, full dentition) for children aged 3 and 4 years in the three study areas combined between the base-line year* and 1962

\begin{tabular}{|c|c|c|c|c|c|c|}
\hline \multirow[b]{2}{*}{ Tooth } & \multicolumn{3}{|c|}{ Children aged 3 years } & \multicolumn{3}{|c|}{ Children aged 4 years } \\
\hline & Base-line & 1961 & Reduction & Base-line & T96I & Reduction \\
\hline a & 0.77 & 0.15 & $8 \mathrm{r}$ & 0.84 & 0.34 & 60 \\
\hline b & 0.49 & 0.10 & 80 & 0.57 & 0.16 & 72 \\
\hline c & 0.24 & 0.05 & 79 & 0.45 & 0.10 & 78 \\
\hline d & $1 \cdot 07$ & $0.4 \mathrm{I}$ & 62 & $x \cdot 56$ & 0.68 & 56 \\
\hline e & $I \cdot 23$ & 0.58 & 53 & $I \cdot 97$ & 1.03 & 48 \\
\hline Total & 3.80 & $1 \cdot 29$ & 66 & $5 \cdot 39$ & $2 \cdot 31$ & 37 \\
\hline
\end{tabular}

Table 7. Percentage reduction in the mean number/child of carious surfaces in children aged 3 and 4 years (deciduous teeth, full dentition) in the three study areas combined between the base-line year* and $196 \mathrm{I}$

\begin{tabular}{|c|c|c|c|c|c|c|}
\hline \multirow{2}{*}{$\begin{array}{c}\text { Tooth } \\
\text { surface }\end{array}$} & \multicolumn{3}{|c|}{ Children aged 3 years } & \multicolumn{3}{|c|}{ Children aged 4 years } \\
\hline & Base-line & I $96 \mathrm{I}$ & Reduction & Base-line & 1961 & Reduction \\
\hline Occlusal & $2 \cdot 07$ & 0.94 & 55 & $3 \cdot 14$ & I.59 & 49 \\
\hline Mesial & $I-73$ & 0.34 & 80 & $2 \cdot 71$ & 0.86 & 68 \\
\hline Distal & $I \cdot 32$ & 0.37 & 72 & $2 \cdot 6 \mathrm{I}$ & 0.87 & 67 \\
\hline Buccal & $I \cdot I \mathbf{I}$ & 0.32 & 71 & $r \cdot 89$ & 0.76 & 60 \\
\hline Lingual & 0.99 & 0.28 & 72 & $I \cdot 76$ & 0.70 & 60 \\
\hline Total & $7 \cdot 22$ & $2 \cdot 25$ & 69 & I2-I I & $4 \cdot 78$ & $6 \mathrm{I}$ \\
\hline
\end{tabular}




\section{Discussion and conclusions}

In the official report on the studies (Ministry of Health, Scottish Office, Ministry of Housing and Local Government, 1962) comparison is made between the findings in Great Britain and those in the Grand Rapids study in the United States (Arnold, Dean, Jay \& Knutson 1956). After adjustment for changes in the control areas, the reduction among children aged 4 years was $42 \%$ in Grand Rapids and $54 \%$ in Great Britain, the corresponding figures for children of 5 years being $45 \%$ and $47 \%$. 'The same order of reduction was thus being achieved in this country as in Grand Rapids, and it is reasonable to expect that over a longer period of fluoridation in this country results for both the deciduous and permanent teeth similar to those in Grand Rapids will be obtained.

The findings from these American and British studies themselves provide clear evidence of the value of fluoridation as a preventive measure against dental caries. In conjunction with the findings from studies in other parts of the world, they provide massive evidence.

\section{REFERENCES}

Arnold, F. A. Jr., Dean, H. T., Jay, P. \& Knutson, J. W. (1956). Publ. Hlth Rep., Wash., 7x, 652.

Ast, D. B., Smith, D. J., Wachs, B. \& Camtwell, K. 'T. (1956). F. Amer. dent. Ass. 52, 3 I 4.

Backer-Dirks, O., Houwink, B. \& Kwant, G. W. (1961). Arch. oral Biol. 5, 284.

Hill, I. N., Blayney, J. R. \& Wolf, W. (1956). F. Amer. dent. Ass. 53, 327.

Hutton, W. L., Linscott, B. W. \& Williams, D. B. (I956). Canad. F. publ. Hlth, 47, 89.

Ludwig, T. G. (I959). N.Z. dent. F. 55, 262.

Ministry of Health, Department of Health for Scotland, Ministry of Housing and Local Government (1953). The Fluoridation of Domestic Water Supplies in North America. London: H.M. Stationery Office.

Ministry of Health, Scottish Office, Ministry of Housing and Local Government (1962). Rep. publ. Hith med. Subj., Lond., no. 105.

Russell, A. L. \& White, C. L. (196r). Publ. Hlth Rep., Wash., 76, 1087.

World Health Organization (1962). Tech. Rep. Wld Hlth Org. no. 2.42.

\section{Fluoridation and public relations}

By A. J. Dalzell-Ward, The Central Council for Health Education, Tavistock House, Tavistock Square, London, W.C.I

\section{Background}

At first glance, it might seem extraordinary that a precise scientific matter like the fluoridation of public water supplies should call for a special public relations policy. There is no public health measure or prophylactic procedure that has been so exhaustively examined and tested. It shares with vaccination against smallpox, alone, the distinction of being based on observations of entirely natural phenomena. The benefits it can offer promise an impressive saving in suffering and money, and the safety margin exceeds that offered by any other prophylactic procedure. It must be remembered, however, that proponents of this measure have encountered opposition in the USA, Sweden, New Zealand, Eire and the UK. 